THURSDAY, FEBRUARY 26, 1885

\section{THE RELATIVE EFFICIENCY OF WAR-SHIPS}

' $\mathrm{HE}$ Times of the Igth inst. contains a long and vigorous criticism by Sir E. J. Reed, M.P., of the ten largest British ships of war "launched in 1879 , or since, or remaining on the stocks." These are the Ajax, Agamemnon, Colossus, Edinburgh, and the six vessels which constitute the Admiral class. These vessels are all built upon the central citadel system-i.e. their armoured portions are merely citadels erected in the middle of the length ; the ends being left without armour-plating. One of these ships may thus be considered as being divided into three parts, so far as her out-of-water structure is concerned. The central part is plated completely around with very thick armour, which extends from the upper deck to several feet below the water-line; while the parts before and abaft this are not protected by armour, but rest upon a thickly plated deck situated at the depth of the lower edge of the citadel armour. This deck protects the bull beneath the armour against the effects of a plunging fire.

This system of construction was advocated by Sir E. J. Reed before the Committee of Naval Designs in $187 \mathrm{I}$. It was first adopted in the Inflexible; and immediately gave rise to a discussion respecting the size of the armoured citadel which Sir E. J. Reed has, with persistent energy, kept up ever since. The Times' letter above referred to is a continuation of the old, and well-remembered, Inflexible debate. A statement of the points then in dispute will be found in NATURE of July I2 and 19, 1877. Sir E. J. Reed maintained that the fighting power of the Inflexible was gravely compromised by the shortness of her armoured citadel-which was not long enough to make the ship stable in the event of her thinly plated ends being so much injured as to lose all power of excluding water. A committee was appointed to inquire into and report upor the matter, but Sir E. J. Reed refused to give evidence before it.

Sir E. J. Reed now says, with reference to the later ships of this type: "I have to state, and am prepared to demonstrate to any competent tribunal, that there is not one of these ten ships, the latest added to the British Navy, that cannot be either capsized and sunk, or sunk without capsizing, without any shot or shell whatever being directed against those parts of the ship which are armoured. . . The French armoured ships . . . must in all reason be expected to dispose of these English ships in a very few minutes by simply destroying their unarmoured parts. . . . I will here repeat in the most public and responsible manner that the Ajax, Agamemnon, Colossus, and Edinburgh, and the six ships of the Admiral class, are all utterly unfit to engage the corresponding French ships; unfit to entcr the line-ofbattle at all; and unfit to be retained on the list of armoured ships."

This is strong language, but not so strong as that which is used respecting the members of the Board of Admiralty and the Constructors of the Navy. Sir E. J. Reed blames Admiral Sir Cooper Key, the First Sea Lord of the Admiralty, for not setting his face against "the prospect VOL. XXX1.--No. 800 of British ship after ship capsizing in battle, before their armour had been violated or touched." He fears that the day may be near "when the present betrayal of our Navy by a set of politicians, admirals, and constructors may wring from us a cry which the very ends of the earth will hear." The Admiralty of the day is "foolish enough, cruel, heedless, reckless, and faithless enough" to rely upon the skill and vigilance of the seamen "whom they send unprotected to destruction"; and "to substitute them for those actual physical defences which the ship herself should embody." Sir E. J. Reed is "fast coming to feel something very like contempt" for the heads of the Admiralty; and he considers that "they are unequal to the work they have undertaken, and have become a source of grave national danger. . . . Upon the heads of the present Board of Admiralty must continue to rest, after this public warning, the responsibility of delivering ten British ships of the largest class an easy and certain prey to destruction should war arise."

These are grave charges; and if the questions involved by them could be settled by forcible or scornful language, there would be little remaining to be said. It is desirable, however, to disregard as much as possible the rhetorical effect of the statements made, and to endeavour to ascertain what are the simple facts of the case. It is important likewise to remember that the comparison instituted between our ships and those of the French is not one between fully armoured and partially armoured ships, but between partially armoured ships on both sides. The armour protection is very limited in the French ships, but it is differently distributed from what it is in ours. The armour of the French ships stops at a very small height above the water-line: and the space between the top of the armour and the upper deck may be destroyed as easily as the unarmoured ends of our ships. Any approach to destruction would completely cripple the fighting power, speed, and manœuvring qualities of these ships.

If the assumptions upon which Sir E. J. Reed's main argument is based are sound and indisputable, then no condemnation of the Board of Admiralty and of the Naval Constructors could be too strong or unqualified. We are disposed to go a long way with him in believing that all is not so well as might be wished with our recent ships, and that there is incompetency and something very like indifference to be found in high quarters at the Admiralty : but, before adopting, in all their breadth and fullness, the views so vigorously and ably advocated by Sir E. J. Reed, there are one or two points upon which we feel that more light is needed. Indecd, we are convinced that the present widely discordant views that are held by the different parties to this naval discussion are impossible of reconciliation until the points referred to are cleared up.

The chief one of all is, Can the thinly-plated ends of these citadel ships be readily destroyed in action and made useless-or worse than useless-for the purpose of contributing buoyancy or stability to the ship? If they can, it is obvious that the ship's safety may be speedily endangered without the thick armour plating of the citadel being penetrated. Sir E. J. Reed assumes that this is unquestionably the case, and he emphatically asserts that our ten most powerful ships of recent construction might 
be disposed of "in a very few minutes by simply destroying their unarmoured parts." It is upon this assumption that his charges against our ships and their constructors are mainly based. If it be correct, the Admiralty stand convicted of culpable neglect or error; but if it be incorrect, or very doubtful, then Sir E. J. Reed's charges are pointless and unjustifiable.

The question is one of most vital importance to the fighting efficiency of nar principal ships of war; but how is it to be settled? It is not one with which mere theory or abstract science cun deal : actual experiment can alone answer it. Sir F. J. Reed believes, and asserts, that such structures as the thinly-plated ends of our recent ironclads may be effectually destroyed in a few minutes, and that single shells may shatter large portions of them into fragments. He says:--." It is not a mere question of viddling the ends, but also one of blowing them up by shell fire: and how effectually they may be thus destroyed was shown at Alexandria, where a single shell, bursting against the unarinoured part of the Superb's side, tore a hole in it Io feet by 4 feet in extent."

The apologists for this system of construction say, on the other hand, that if the area is increased over which the armour is spread, as would be the case if the citadels were lengthened, the thickness of armour throughout would require to be reduced; and the armour protection would therefore be less in the central portion of the ship which incloses the boilers, engines, and other essential elements of fighting cificicncy. Many naval artillerists say, further, that unless the ends can be plated with the very thickest of armour, it is better to include everything which contributes to fighting power within the armoured citadel or bclow the armoured deck, and to make the ends as thin as possible. They argue that shells which meet with considerable resistance in penetrating armour of moderate thickness will shatter the ship's sicle, and make boles which cannot be stopped; whereas they almost invariably make clean holes through thin plating, and would, in the vast majority of cases, pass through the ship and out upon the other side. Such an instance as Sir E. J. Reed calls attention to in the case of the Superb would not, it is said, occur in practice more than once in one hundred times. The clean holes made by shells in thin plating can be stopped effectually and quickly by men stationed inside with shot-hole stoppers. These are made of india-rubber, and open and close like an umbrella. They are pushed out from the inside, and then pulled back and opened over the outside of the hole. The buoyancy and stability afforded by the ends can, it is confidently stated, be preserved by these means; whereas the damage done to any but the very thickest of armour plating would be so much greater that the holes made by shells could not be so effectually dealt with.

It is also pointed out that it is extremely difficult to strike a ship exactly at her water-line. The great majority of projectiles strike at some distance above it. If they are aimed too low they ricochet from the ivater surface and strike the ship above the water-line. It is most difficult to penetrate a ship exactly at her water-line; and if she is so penctrated, the holes may be much more readily and effectually stopped when the plating is thin than when it is thick. This is the argument which forms the answer to Sir E. J. Reed's charges.
Sir E. J. Reed says that "the reply to the British ships which are being made to depend for their flotation and stability upon their unarmoured cnds will inevitably be small-gun attack," and he considers that even the fire from machine-guns may be sufficient to cripple them. This opens up a complicated question and one which cannot be fully considered in all its details from a merely abstract point of view. There is obviously, however, a limit to the effective use of small gun and machine-gun fire, which is imposed by the necessity of protecting them by armour if they are to fight at short range. If the guns are not protected by armour they can only be relied upon at long ranges; and cven then they may as readily be placed hors de combat by the fire from the enemy as succeed in penetrating, still less in destroying, the unarmoured ends of the latter.

These are points which experience alone can throw any clear and definite light upon. Each party may continue to advocate its own view with great show of reason, but neither will convince the other till the effect of artillery fire upon such structures as the unarmoured ends of the ships in question has been thoroughly tested. In the meantime the public mind is only being bewildered and wearicd by the reiterated discussions of questions which cannot be settled by mere argument or force of words.

A structure similar to the unarmoured ends of one of our ships might easily be built and placed afloat. It should then be fired at from various distances with guns of different sizes. Valuable data might then be obtained upon two crucial points: (1) the percentage of shots which would strike sufficicntly near the water-line to affect prejudicially the buoyancy or stability ; and (2) the nature of the holes that would be made; whether such as are capable of being easily stopped from the inside, or such as admit of no effectual stoppage, but practically constitute a disintegration or destruction of the fabric. This simple experiment might surely be made in such a way as to set at rest the discussion that has now been going on for so many years respecting the efficiency of the system upon which the safety and fighting power of our most powerful ships depends. Still, "water conditions" would be the most favourable for such experiments ; because it would obviously be more difficult to make good practice at a vessel's water-line in action-under the ordinary circumstances, at sea, of rolling motion and the relative movements of the vessels engaged-than at a quiet and carefully arranged trial.

The only logical and effective answer that can be made to Sir E. J. Reed's letter is that which would be furnished by the rcsults of experiments such as we have indicated; and that answer cannot be made too soon, or too complete, either for the reputation of the Admiralty and of the Constructors of the Navy-who, to say the least, appear to be greatly in the dark respecting the practical merits of the system to which they are committed-or for th : satisfaction of the public mind.

'This question, upon the merits of which Sir E. J. Reed's charges must either stand or fall, is one which only Science can settle by experimental tests; but there is an important point underlying another assumption contained in his letter which may be discussed with advantage from a more abstract point of view. He says: "The Admiralty Director of Naval Construction, in the article 'Navy,' in the 'Encyclo- 
pædia Britannica,' lays down the following principle :'The fairest available approximate measure of the power of the ships is their displacement or total weight. It always represents power of some kind.'" Sir E. J. Reed adopts this principle, without reserve or qualification, and employs it as an empirical method of determining the relative fighting powers of the ships of our own and the French navies.

"Bearing this principle in mind, as one accepted and avowed by the Admiralty" he proceeds to compare the displacements of ten of the largest French ships recently built with ten of the corresponding ships of our own navy. The following result is arrived at:- "Looking at these figures, and bearing in mind the doctrine quoted-that superior displacement means superior power, and inferior displacement inferior power-we here see that the English ships have been deliberately made inferior by our Admiralty, ship by ship and squadron by squadron."

We do not know what authority there is for saying that this "principle" is accepted and avowed by the Admiralty. 'True, it is propounded by Mr. Barnaby, the Director of Naval Construction, in the latest edition of the "Encyclopædia Britannica"; but we have not heard that the Admiralty accept and avow it. We hope, for the sake of the scientific reputation of the Naval Department, that they hold no such fallacious and absurd doctrine. It is surprising to find a scientific man of Sir E. J. Reed's eminence and ability assenting to, and adopting, Mr. Barnaby's so-called "principle." What is stranger than all, however, is that Sir E. J. Reed should not see that the adoption of it is inconsistent with his main contention that our ten newest armour-clads are practically worthless, for quite other reasons, as compared with those of the French, and could be disposed of by the latter "in a very few minutes."

The average displacement of the ten English ships referred to by Sir E. J. Reed is 9,363 tons, and that of the corresponding ten French ships is 10,470 tons. Applying Mr. Barnaby's principle in the sense in which it is used by Sir E. J. Reed-bearing in mind that "superior displacement means superior power, and inferior displacement inferior power," and that "the fairest available approximate measure of power" is "displacement or total weight"--we arrive at the conclusion that the fighting power of the ten English ships is rather less than ninetenths that of the French ships. Had their displacements been greater they would, upon the same principle, have been more powerful than the French ships. But Sir E. J. Reed believes that, apart from displacement altogether, and because of the different systems of construction cmployed in the two cases, the English ships could be sunk by the French ships in a very few minutes. The assumptions upon which the respective arguments are based are obviously inconsistent with each other. One is that the English ships are inferior to those of the French because their displacements are less; the other is that they are inferior because the details of their construction are not so wisely and efficiently designed. Either one or both assumptions may be correct; but the one has no necessary relation to the other.

But we will compare Mr. Barnaby's present principle with an empirical formula previously laid down by him for determining the comparative efficiency of ships of war. In the course of a lecture delivered in the Royal United Service Institution, in 1872 , upon "Modern Ships of War," Mr. Barnaby put forward the following formula :--

$$
\frac{\mathrm{A} \times \mathrm{G} \times \mathrm{H} \times \mathrm{S}^{3}}{\mathrm{~L} \times \mathrm{IOO}}=\text { comparative efficiency, }
$$

where A. is the weight of armour per ton of ship's measurement, $G$ the weight of protected guns and ammunition, $H$ the height of battery port-sills above load water-line, $\mathrm{S}$ the speed in knots at the measured mile, and $L$ the length of the ship.

Mr. Barnaby applied this formula to the seven ironclads named in the table given below. In this table we have placed, alongside the names of the vessels, a column which contains their displacements in tons. The next column contains their comparative efficiencies, as computed by the above formula; and the last column contains their comparative efficiencies, upon Mr. Barnaby's new principle that displacement is a fair measure of power. It will be seen that, according to the latter, the most powerful of these seven ships is the Minotaur, and the next the $W$ arrior. The relative efficiency of the former vessel is three times greater than that given by Mr. Barnaby's previous formula; and the latter is nearly four times greater. The Warrior and the Minotaur are, according to this standard of comparison, the most powerful of the seven ships named; while the Minotaur would, upon the same principle, be classed as the most powerful fighting ship the British navy possesses at the present time - with the single exception of the Inflexible. In reality, however, the Warrior and Minotaur are the weakest and least efficient ironclads we possess; and are invariably classed as obsolete even in the most favourable estimates that are made of the fighting power of the British navy.

\begin{tabular}{|c|c|c|c|c|c|}
\hline $\begin{array}{l}\text { Names of } \\
\text { ships }\end{array}$ & $\begin{array}{l}\text { Displacement } \\
\text { in tons }\end{array}$ & & $\begin{array}{l}\text { elative efficiencie } \\
\text { as computed by } \\
\text { Mr. Barnaby's } \\
\text { formula, } \\
A \times G \times H \times \mathrm{S}^{3}\end{array}$ & & $\begin{array}{l}\text { Relative effi- } \\
\text { ciencies upon } \\
\text { principle that } \\
\text { power varies with } \\
\text { displacement }\end{array}$ \\
\hline & & & $\mathrm{L} \times$ I00 & & \\
\hline Monarch & 8,320 & $\cdots$ & $149 \cdot 8$ & $\cdots$ & $149^{\circ} 8$ \\
\hline Fiercules & $\ldots 8,680$ & $\ldots$ & II 34 & $\ldots$ & $156 \cdot 2$ \\
\hline Captain & 7,900 & $\cdots$ & $83 \cdot 3$ & ... & $142 \cdot 2$ \\
\hline Vanguard & 6,010 & $\cdots$ & $8_{3} \circ$ & ... & $108 \cdot 2$ \\
\hline Minotaur & ... I0,690 & $\ldots$ & $6 r \cdot r$ & $\ldots$ & 192.4 \\
\hline Warrior & $\ldots 9,2 \mathrm{ro}$ & $\ldots$ & $44 \cdot 5$ & $\cdots$ & 165.8 \\
\hline Defence & $\ldots 6,150$ & $\ldots$ & 10.9 & $\ldots$ & 110.7 \\
\hline
\end{tabular}

Nothing further can be necessary to show the fallacy, and the absolute inconsistency, of the views put forward at various times by $\mathrm{Mr}$. Barnaby, respecting the standard by which the fighting power of a ship, or of a navy, may be judged. He has given no justification of either of the methods described; nor attempted to show that they are approximately reliable. The formula laid down by him in 1872 recognises that the fighting power of a ship of war is made up of various distinct and independent elements-that the amount of armoured protection, as represented by weight of armour; the power of the armament, as measured by its weight; the speed, and other qualities constitute elements of fighting power, which have different relative values, and which must be separately taken into account. We here find the value of manouvring power, or handiness in turning, recognised by introducing the length of the ship as a divisor into the ${ }^{10}$ rmula. This element of fighting power is assumed to 
vary inversely as the length; so that, in similar ships, it would vary inversely as their displacements. In other words, so far as one element of fighting power is concerned, and that a very important one, the measure of its amount is not the displacement, as Mr. Barnaby now assumes, but the inverse ratio of the displacement.

The fighting power of a ship is thus composed of several diversc and independent elements; and there is nothing approaching to a consensus of professional opinion as to the relative importance of these elements. To assume that they all vary together with the ship's dimensions, or with her weight in tons, is in the highest degree delusive and absurd. The displacement of a ship measures her weight and nothing more. Whether that weight has been effectively and wisely employed in developing a high degree of fighting power, is an entirely independent matter ; and one upon which the whole question of fighting efficiency depends. The statement that displacement "always represents power of some kind," merely begs the question. Of course it represents power; but such power is simply that of displacing water. It may represent that and nothing more, or it may represent in addition the possession of great fighting power, or of other desirable qualities. I3ut the possession of such qualities, and the degree in which they will be developed, must depend entirely upon the skill of the designer-an arbitrary personal factor which is not always limited by the cubic feet of displaced volume that are placed at his disposal. Mr. Barnaby himself pointed out in the paper above referred to, that although the Defence and Vanguard have approximately equal displacements, the latter carried one-half more armour-plating than the former upon threefourths of the weight of hull; and was so superior in manouvring capability that she would turn completely around in four and a half minutes, whereas the former vessel required seven minutes to complete a circle. This difference in qualities, and superiority in fighting power, of the Vanguard over the Defence is absolutely undiscoverable by merely comparing the displacements.

All the comparisons we have seen of the fighting powers of modern ships of war and of our own and foreign navies, have been more or less vitiated by the arbitrary standards that have been selected as the basis of such comparisons. The displacement basis is unreliable and misleading, and furnishes no test whatever of fighting power. It would be extremely difficult to devise any simple standard by which the popular mind may be fairly impressed with the relative powers of our own and foreign navies ; while for purposes of exact comparison or of technical discussion no such standard could be regarded as absolute. Before a simple standard or unit of comparison can be framed, which will be satisfactory or useful, naval officers, artillerists, and constructors require to agree among themselves about the relative importance of the various elemenls that make up the fighting power of a ship. The defensive values of armour-plating, speed, turning-power, and other protective qualities, and also the offensive values of the gun and torpedo armaments, the ram, speed, \&c., require to be separately evaluated and their relative importance determined. If a general agreement could be arrived at as to the relative approximate values of each of these independent elements of offensive and defensive power, an cmpirical formula might be framed
- such as Mr. Barnaby attempted with insufficient data in $1872-$ which would fairly represent the gross fighting efficiency of a ship. Till this is done, no rule can possibly be devised which will indicate anything more than the mere opinions of the person who frames it ; while often, as in the case of Mr. Barnaby's present displacement basis, the application of the rule may be misleading in a degree which its framer could never have foreseen or intended.

Sir E. J. Reed's letter to the Times, and the whole force of the charges contained in it, rests mainly upon the truth of the two assumptions we have considered. The first is that the unarmoured ends of our present ironclads have practically no protective value. This is a point which, as we have said, may be determined once and for all by scientific expcriments. The second assumption is that the comparative efficiency of our own ships and those of foreign powers may be approximately measured by merely comparing their displacements. This proposition is unsound, and does not admit of any qualifying corrections short of depriving it of all specific meaning. A scientific standard or unit of comparison which may be fairly applied to the approximate determination of the relative fighting powers of war-ships and navies is greatly to be desired; but before such an one can be framed, the per. sons who have to use our ships of war and to take them into action, and those who are responsible for their efficient construction, must come to some definite understanding as to what the various elements of fighting power consist of, and what are their relative degrees of importance ; and to do so they must call in the aid of Science.

\section{PROFESSOR WILLIAMSON'S DYNAMICS}

An Elementary Trealise on Dynamics, containing Applications to Thermodynamics, \&sc. By Benjamin Williamson, F.R.S., and Francis A. Tarleton, LL.D. (London: Longmans, Green, and Co., 1885.)

PROFESSOR WILLIAMSON is already so well known to the student by his excellent text-books of the Differential, and of the Integral, Calculus, that his appearance in a new field of authorship is sure to excite attention. We accordingly opened the present work with expectations of a very high order. Not, of course, expectations that much novelty of matter could be introduced in an elementary work on a subject which has been thoroughly threshed-out, but that possibly fresh interest and easier assimilability might be given to long-known facts and processes by some novel mode of presentation.

In these expectations we have been disappointed. Either the subject of Dynamics does not admit of treatment superior to that which it has already received, or our authors are not destined to be the pioneers to the possible improvements. Our special reasons for this statement we will give with some detail, but we may begin with some general observations.

From the time in which Jackson, Lloyd, Whewell, and many others, introduced continental methods to the average Honour-man; through the period of Earnshaw, Pratt, Wilson, Tait and Steele, Griffin, Walton, \&c., to the Parkinson, Bezant, Routh, \&c., of the present day, there has been a plethora of treatises in English on the various parts of elementary Dynamics. Some of these 